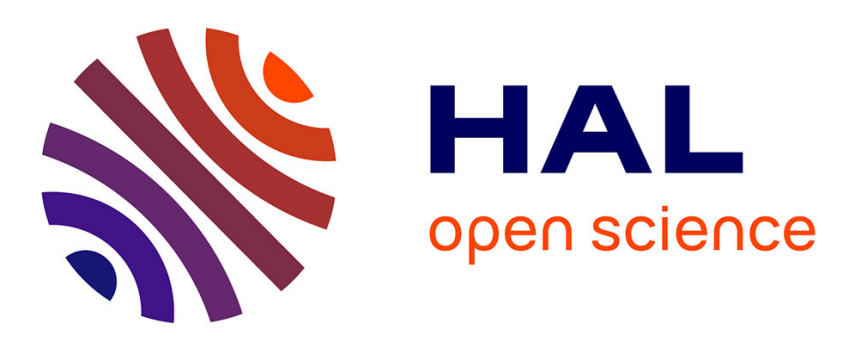

\title{
The blossoming of children's multimodal skills from 1 to 4 years old
}

Aliyah Morgenstern

\section{To cite this version:}

Aliyah Morgenstern. The blossoming of children's multimodal skills from 1 to 4 years old. Cornelia Muller, Alan Cienki, Ellen Frickee, Silva Ladewig, David McNeill, Jana Bressem. Body - Language Communication. An international Handbook on Multimodality in Human Interaction, 2, De Gruyter, pp.1848-1857, 2014, Handbücher zur Sprach- und Kommunikationswissenschaft, 978-3-11-030080-2. halshs-01350598

\section{HAL Id: halshs-01350598 \\ https://shs.hal.science/halshs-01350598}

Submitted on 31 Jul 2016

HAL is a multi-disciplinary open access archive for the deposit and dissemination of scientific research documents, whether they are published or not. The documents may come from teaching and research institutions in France or abroad, or from public or private research centers.
L'archive ouverte pluridisciplinaire $\mathbf{H A L}$, est destinée au dépôt et à la diffusion de documents scientifiques de niveau recherche, publiés ou non, émanant des établissements d'enseignement et de recherche français ou étrangers, des laboratoires publics ou privés.

\section{(ㅇ)(1) $\$$}

Distributed under a Creative Commons Attribution - NonCommercial - NoDerivatives $\mid 4.0$ 
Morgenstern, A. (2014). The blossoming of children's multimodal skills from 1 to 4 years old. In Cornelia Muller, Alan Cienki, Ellen Frickee, (Eds.). Body - Language - Communication. An international Handbook on Multimodality in Human Interaction. Berlin : De Gruyter Mouton. 1848-1857.

\title{
215. The blossoming of children's multimodal skills from 1 to 4 years old
}

\author{
1. Introduction \\ 2. Background \\ 3. Multimodal skills from 1 to 4 \\ 4. Conclusion \\ 5. References
}

\begin{abstract}
Language acquisition is one of the first fields in which the multimodal aspects of language have been illustrated. Spontaneous longitudinal interactional data was required to study productions in context and the obvious role of action, gaze, gesture, facial expressions and prosody in children's first productions was underlined by a wealth of studies. However, most research focuses on children's first symbolic gestures and on word-gesture combinations in the first stages of development. But children, continue to use their body, and especially manual gestures, bead shakes, facial expressions throughout the language acquisition process and become expert multimodal language users in face-to-face conversations. This short paper explores the blossoming of children's multimodal skills through two exploratory studies on children's expression of negation and on pointing gestures from one to four years old. Research based on video-data of children's daily interactions can demonstrate the progressive mastery of coordination between bodily action, gestures and talk in conversation. Children can rely on simultaneous use of the vocal and visual modalities to gradually become competent multimodal conversationalists.
\end{abstract}

\section{Introduction}

Gestures, verbal productions, signs, gaze, facial expressions, postures, are all part of our socially learned, inter-subjective communicative system. Human beings, with all their representational skills, combine modalities in order to share meaning, to refer to present and absent entities and events, to express their projects, their desires and their inner feelings. As McNeill pointed out, we might need to "broaden our concept of language" (1992: 2). Research in Sign Languages has helped to show how the visual modality can be used symbolically. Thanks to combinations of experimental and ecological studies, to video recordings, to specialized software, international databases, theoretical approaches that include multimodality and multiple levels of analyses, and to rich collaborations among experts of several scientific fields, we now have the tools that help us create new methods to illustrate the fact that "vocal language is inherently multimodal” (Müller 2009: 216).

"Utterance uses of visible bodily action" (Kendon 2004: 1-2) integrated with spoken expressions, form a tight partnership in adult interaction in which they can either alternate or be complementary. The roots of this partnership have been illustrated in a wealth of research in language acquisition, one of the first fields for which the role of gestures has been analyzed in 
Morgenstern, A. (2014). The blossoming of children's multimodal skills from 1 to 4 years old. In Cornelia Muller, Alan Cienki, Ellen Frickee, (Eds.). Body - Language - Communication. An international Handbook on Multimodality in Human Interaction. Berlin : De Gruyter Mouton. 1848-1857.

depth. However, most of the studies are focused on the first stages of language development and on how gestures facilitate children's entry into

(i) the symbolic power of language because they are enactive and iconic (Werner and Kaplan 1963) and

(ii) into syntax through first word-gesture combinations.

In this short essay, I would like to argue that gestures remain functional when hearing children progressively master speech. I will make a quick overview of the background for my research. I will then use two studies to illustrate the blossoming of children's multimodal skills after the first stages of language development: children's multimodal expression of negation and a longitudinal case-study of a child's pointing gestures, from one to four years old.

\section{Background}

\subsection{Action, context, experience and the body in language acquisition}

\subsubsection{Language in action}

Language - a social phenomenon - is captured, internalized and reconstructed again and again by each individual child thanks to its transmission by care-givers in their daily interactions with their upspring. "Meaning comes about through praxis - in the everyday interactions between the child and significant others" (Budwig 2003: 108). Joint parent-child action/interaction provides the scaffold for children's growing ability to grasp both what is happening around them, and what is being said in the situation. They learn to understand language and action together, each providing support for the other. Following Vygotsky (1978), Duranti explains that language is "a mediating activity that organizes experience" (1984: 36) but of course, experience is reversely a mediating activity that organizes language. To examine how children come to use language in general, one must examine the broader context in which the child experiences events and interaction: "Experience, even the drama of pain and suffering, lies outside, inside, and alongside enacted language as its indexical and phenomenological resource" (Ochs 2012: 156).

\subsubsection{Language in context}

The starting point of language acquisition scholars' interest in gesture or visible bodily action could be summarized in de Laguna's famous assertion that "in order to understand what the baby is saying you must see what the baby is doing" (1927: 91). Children's productions are like evanescent sketches of adult language and can only be analyzed in their interactional context by taking into account shared knowledge, actions, manual gestures, facial expressions, body posture, head movements, all types of vocal productions, along with the recognizable words used by children (Morgenstern and Parisse 2007; Parisse and Morgenstern 2010). Research in language 
Morgenstern, A. (2014). The blossoming of children's multimodal skills from 1 to 4 years old. In Cornelia Muller, Alan Cienki, Ellen Frickee, (Eds.). Body - Language - Communication. An international Handbook on Multimodality in Human Interaction. Berlin : De Gruyter Mouton. 1848-1857.

acquisition has therefore developed the tools, methods and theoretical approaches to analyze children's multimodal productions in context as early as the second half of the $19^{\text {th }}$ century, through scientist's observations of their own children. The detailed follow-ups of children's language anchored in their daily lives are a source of fascinating links between motor and psychological development, cognition, affectivity and language. The "founding fathers" of the study of child development and language had great intuitions about the importance of gestures and their relation to language. In his notes on his son's development, Darwin (1877) stresses the importance of observing the transition from uncontrolled body movements to intentional gestures. Romanes (1889) compares human and animal gestures. He makes new observations on qualitative differences and mentions the "gestural language of deaf people" as a sign of the universality of symbolic gestures.

As of the end of the $20^{\text {th }}$ century, thanks to video data linked to transcripts with specialized software (CLAN, ELAN, PHON) detailed codings and analyses of multimodality have been possible and have opened whole new fields of research. It is especially the case for researchers who study language with a usage-based perspective in its natural habitat - discourse, daily conversations - "the prototypical kind of language usage, the form in which we are all first exposed to language - the matrix for language acquisition" (Levinson 1983: 284). We are now able to document in detail how the visual and vocal modalities come together in a constant stream in daily interactions and progressively shape children's language.

\subsubsection{From sensorimotor schemas and motor representations to language}

Zlatev (1997) suggests that sensorimotor schemas provide the "grounding" of language in experience and will then lead to children's access to the symbolic function. Infants' imitation and general production of gestures has indeed been studied as a prerequisite to construct "prelinguistic" concepts, as a pathway into the symbolic function of language or a bridge between language and embodiment. Gestures are viewed as representational structures that are constructed through imitation, that are enacted overtly and can be shared with others. Mimetic schemas for imitable actions, shared representations of objects that can be manipulated, ground the acquisition of children's first gestures and first words or signs (Zlatev, Persson, and Gärdenfors 2005). Besides, evidence accumulated in neuroscience shows that language use engages motor representations (Glenberg and Kashak 2003) and that through complex imitation, manual-gestural communication in social interaction leads to language (Arbib 2012). 
Morgenstern, A. (2014). The blossoming of children's multimodal skills from 1 to 4 years old. In Cornelia Muller, Alan Cienki, Ellen Frickee, (Eds.). Body - Language - Communication. An international Handbook on Multimodality in Human Interaction. Berlin : De Gruyter Mouton. 1848-1857.

\subsection{The facilitating role of gestures in language acquisition}

Children's neurological maturation enables them to control their bodily movements and transform them into gestures thanks to gradually finer motor skills. Some of these gestures are assigned meaning by their interlocutors. First gestures, just before the first birthday, are usually deictic: pointing at an object or waving an object to show it to the parent and attract joint attention. Pointing gestures in particular, combine motor and cognitive prerequisites with the capacity to symbolize and to take up forms used by adults in dialogue. As Tomasello and his colleagues underline, "pointing may thus represent a key transition, both phylogenetically and ontogenetically, from nonlinguistic to linguistic forms of human communication" (Tomasello, Carpenter, and Liszkowski 2007: 720).

At around one year old, children produce representational gestures using their entire body to imitate an animal for example. Children also start using gestures that reflect those in their input around the same period (Estigarribia and Clark 2007). They develop cognitive prerequisites that allow them to take up symbolic gestures such as the "bye bye" gesture, or the "itsy bitsy spider" routine, from the environment.

Gestures have been studied mostly either in the stage called "pre-linguistic" when they are used in isolation, or when they are combined with words and are described as facilitating children's access to first combinations. Synchrony and asynchrony have been presented as important features in multimodal multi-element communication. Kelly (2011) has observed in her data how children's interaction skills unfold from communications across a single modality to multi-modal synchronized communications. Goldin-Meadow and her colleagues have thoroughly investigated productions of gesture-speech combinations and their comprehension at the oneword stage and beyond (Goldin-Meadow 1999; Morford and Goldin-Meadow 1992; Özçalı kan and Goldin-Meadow 2005). They observe that children first use the two modalities to communicate about the same element like holding up a cookie and saying "cookie" (Butcher and Goldin-Meadow 2000). Later on, speech and gesture will together form an integrative system (Goldin-Meadow and Butcher 2003). Using two modalities for two different elements is described as preceding the onset of two-word speech. The skills to express more than one element or aspect of an event in the same turn as opposed to what Scollon (1976) calls "vertical constructions" (different elements expressed in two successive turns that are often united in parents reformulations), are necessary for children to be able to combine two words. The multifaceted character of an event is first expressed through two complementary modalities, with a gesture and a word referring to two different elements. 
Morgenstern, A. (2014). The blossoming of children's multimodal skills from 1 to 4 years old. In Cornelia Muller, Alan Cienki, Ellen Frickee, (Eds.). Body - Language - Communication. An international Handbook on Multimodality in Human Interaction. Berlin : De Gruyter Mouton. 1848-1857.

There is little research on children's gestures when they become more expert speakers apart from very interesting studies on co-verbal gestures used for example to solve problems when they are quite older (Church and Goldin-Meadow 1986; Goldin-Meadow et al. 2001).

However, child language does not cease to be multimodal between two and seven years old. Children's multimodal skills keep blossoming and the conjoined use of the visual-manual and auditory-vocal channels is mastered progressively with great individual differences between children.

\section{Multimodal skills from 1 to 4}

\subsection{Data}

In order to study the use of multimodal skills, video data is necessary. The camera should not only focus on the child but capture the interlocutors as is of course absolutely necessary in sign language interactions. Such video data is extremely rare because focus on the multimodal aspects of spontaneous conversation is quite recent. The CoLaJE team therefore filmed a set of French children from 0 to 7 years old (the Paris Corpus), in one case with two cameras, in order to make fine-grained analyses of gestural aspects of the interaction. The Paris Corpus was financed by the French Agence Nationale de la Recherche, in the context of a research program titled 'Communication Langagière Chez le Jeune Enfant' (CoLaJE, 2009-2012, http:/ / colaje.risc.cnrs.fr where videos and transcriptions can be downloaded) and directed by Aliyah Morgenstern.

All the children live in Paris or in surrounding suburbs. They have middle-class collegeeducated parents, and were filmed at home about once a month for an hour in daily life situations (playing, taking a bath, having dinner). ELAN was the main software used to code gestures. Multimodal analyses require attention to so many details and expertise in so many fields that collective research is necessary to capture all the features of the integrative nature of language with all its linguistic levels and multichannel specificity.

\subsection{Individual differences: the expression of negation}

The CoLaJE team, the team that collected and analyzed the Paris Corpus, has constantly pointed out great disparities between the children's language development (see for example Morgenstern 2009; Morgenstern et al. 2010; Morgenstern and Parisse 2012a, b). The study of the expression of negation is a privileged locus to combine multimodal analyses of gesture with prosody, syntax, semantics and pragmatics. In our preliminary research on five CoLaJE children's multimodal expression of negation (Blondel et al. 2012) we explored the status and evolution of gestures of negation produced with and without words as well as the role of co-verbal gestures used in combination with negative verbal productions. Our main findings were the following. 
Morgenstern, A. (2014). The blossoming of children's multimodal skills from 1 to 4 years old. In Cornelia Muller, Alan Cienki, Ellen Frickee, (Eds.). Body - Language - Communication. An international Handbook on Multimodality in Human Interaction. Berlin : De Gruyter Mouton. 1848-1857.

Interestingly enough some children, but not all of them, followed a prototypical pathway:

(iii) actions of avoidance and rejection mobilizing the whole body;

(iv) symbolic gestures of negation (mostly head-shakes);

(v) gestures of negation used in combination with words;

(vi) negative utterances;

(vii) negative utterances sometimes complemented by co-verbal gestures (negations but mostly other types of gestures).

The child who used gestures of negation in isolation the most clearly, for the longest period and who maintained them in combination with "non" (French)/ "no" (Italian) for the longest time, was the bilingual French/Italian child who took some time to master speech. The necessity to enter two languages at once might have an influence on the management of the visual-gestural and the auditory modalities. In his bilingual environment, gestures of negation were culturally the same in French and in Italian and were used both by his mother and his father. Besides, the headshake is one of the only frequent and clear gestures expressed with the head, which is the part of the body interlocutors constantly have their gaze on when they communicate (Zlatev and Andrén 2009). They might be a stable element to seize in his input and put into use efficiently in all circumstances. Besides, his 4-year-old brother is a very talkative little boy and invades the whole sound environment. Antoine might resort to gesture in order to communicate without interference. Gesture might therefore have a compensatory function for that little boy. It is a wonderful resource to communicate efficiently in his specific environment during his multimodal, multilingual entry into language.

Madeleine, the most linguistically precocious child in our dataset did not use any gesture of negation at the beginning of the data. Her body movements did express avoidance, rejection and refusal but she started using the word "non" at one year old. The first headshakes were co-verbal gestures and we only found them in the data at four years old.

All the hearing children we studied who had used symbolic gestures of negation at first, stopped using them during the period when they entered speech and until their speech was quite continuous as if they needed to concentrate on one modality at a time in the acquisition process. However, the visual-gestural modality made a spectacular comeback in all five children's data with the use of co-verbal gestures of negation when speech seemed to be already quite elaborate.

But do gestures in general disappear from children's interactive communication between the first stages of language development and mastery of speech? Madeleine's data might give us some insight on her use of the visual-gestural modality. We will focus on the use and functions of pointing gestures in her data. 
Morgenstern, A. (2014). The blossoming of children's multimodal skills from 1 to 4 years old. In Cornelia Muller, Alan Cienki, Ellen Frickee, (Eds.). Body - Language - Communication. An international Handbook on Multimodality in Human Interaction. Berlin : De Gruyter Mouton. 1848-1857.

\subsection{Madeleine's use of pointing gestures}

Our analyses of the data (Morgenstern et al. 2010) show that vocal and gestural modalities are associated and complement each other from the very onset of pointing. We categorized all Madeleine's pointing gestures and the adults' in order to analyze their quantity and functions from their "pre-linguistic" to their co-verbal uses.

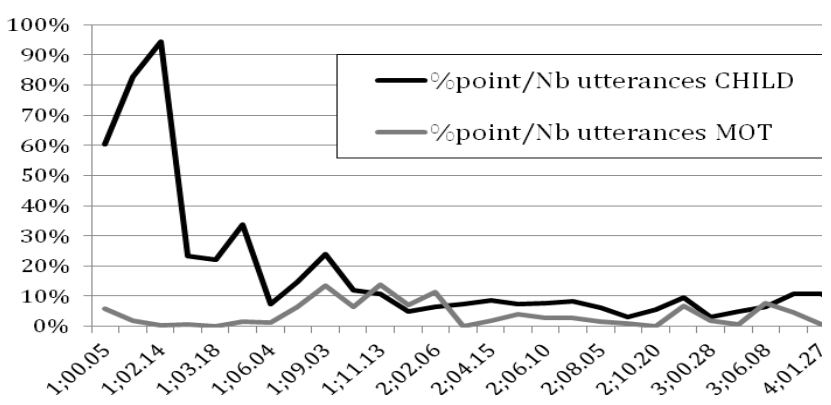

Fig. 215.1: $\quad$ Rate of Madeleine and her mother's pointing gestures over the number of utterances

As shown in Figure 215.1, the increase in Madeleine's use of speech over pointing gestures is spectacular: the rate of her pointing gestures over the number of utterances is much higher at the beginning of the data until she is about 2;0 (up to $93 \%$ at 1;02) and then stabilizes around 5 to $10 \%$ as of $1 ; 06$, which is quite close to her mother's use. In a previous study, we have shown that Madeleine's uses of deictics is complemented by pointing gestures $100 \%$ of the time at the beginning of the data, and only $5 \%$ of the time at 2;0 (Mathiot et al.). But the gross number of pointing gestures used in an hour is in fact still quite important at the end of the data. She produces 95 pointing gestures in one hour at 4;01.27 for example (Figure 215.2). The variation is of course very much linked to situational factors (reading with her mother elicits a lot of pointing gestures).

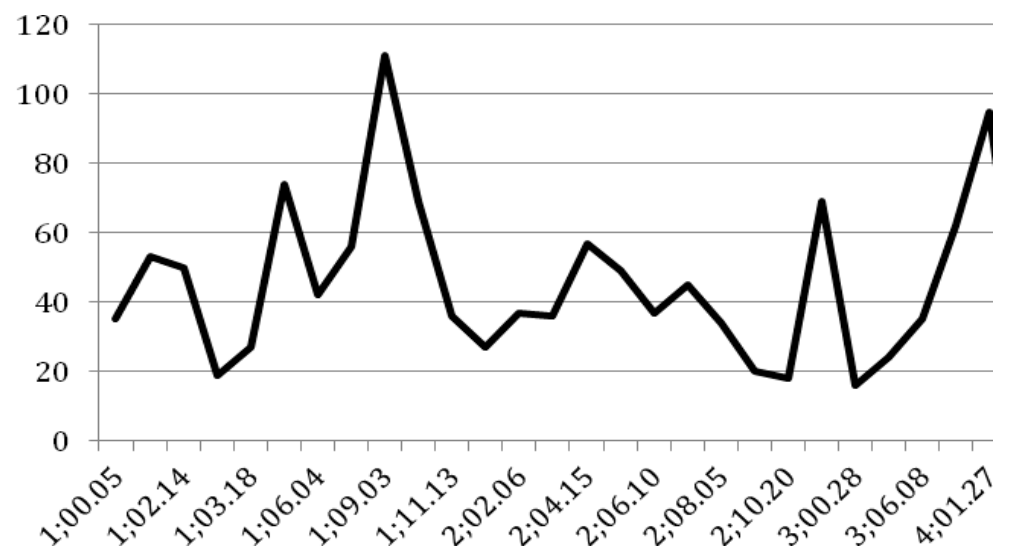

Fig. 215.2: $\quad$ Number of pointing gestures per hour in Madeleine’s data 
Morgenstern, A. (2014). The blossoming of children's multimodal skills from 1 to 4 years old. In Cornelia Muller, Alan Cienki, Ellen Frickee, (Eds.). Body - Language - Communication. An international Handbook on Multimodality in Human Interaction. Berlin : De Gruyter Mouton. 1848-1857.

The functions of Madeleine's pointing gestures diversify greatly over the course of the data. A more detailed analysis of Madeleine's pointing gestures is presently being conducted by Dominique Boutet and the author. At first, pointing gestures are produced in isolation with either a proto-declarative or a proto-imperative function. At around one year old, they begin to be complemented with vocal productions with the same overall functions. Around 1;06, pointing gestures are produced with deictics or nouns and clearly localize the objects shown or requested. The verbal productions simultaneous to pointing then become more and more complex: first with predicates, then with whole utterances. A 2;0, we find the first use of a pointing gesture with a totally different symbolic meaning that can be glossed as "beware!". The Index is vertically held in front of her chin, the tip at the height of her mouth. She is speaking to her doll and telling her "faut pas attraper froid" ('you mustn't catch cold'). She also starts pointing to absent entities. At 2;06 she points to several locations during her fictive narratives. She also starts using more diversified co-verbal gestures. At 3;0, her speech becomes extremely complex with embedded clauses and diversification of her tense system and in parallel she goes through what McNeill (2005) calls "the gesture explosion" with more and more co-verbal gestures.

Interestingly enough, Madeleine enters a different stage around 3;06-4;0 when the functions of her pointing gestures become more and more diverse. For example, she points up her fingers to count the dolls she is talking about, but she also then uses her pointed fingers to embody/stand for the dolls themselves as if they were classifiers in sign language.

By the age of 4;0, her pointing gestures are integrated in fluid co-verbal gesturing. Pointing can follow the rhythmic variation of her prosody: gestures and vocal productions are linked with great subtlety. She demonstrates excellent mastery of the location, the orientation, the motion of her pointing gestures, which enables her to mark subtle differentiation of their functions. She uses pointing to refer to time-spans or to attenuate, to suspend the predication she is making in speech. For example, as she wants to go get a costume that is in her room and disguise herself, she forbids the observer who is filming her to come with her. She lifts up her left index near her chin as she says "je dois chercher mon déguisement" ('I must go get my costume'). She starts to walk towards her bedroom stealthily and her index continues to go upward almost as if she were going to go "shsh". We interpreted that co-verbal gesture as an attenuation of the assertive prohibition she targeted at the observer Martine, whom she might not want to be that directive with. It is a kind of modalisation of the prohibition. There is a message in her whole behavior that seems to mean "beware" but she wants to be gentle about it. And she ends this scene by saying "tu me suis pas hein?" ('you're not following me, OK?'). 
Morgenstern, A. (2014). The blossoming of children's multimodal skills from 1 to 4 years old. In Cornelia Muller, Alan Cienki, Ellen Frickee, (Eds.). Body - Language - Communication. An international Handbook on Multimodality in Human Interaction. Berlin : De Gruyter Mouton. 1848-1857.

Her very sophisticated gesturing therefore illustrates, specifies, reinforces or modalizes the meanings of her vocal productions.

\section{Conclusion}

Gestures continue to enhance the blossoming of children's communication skills after the "pre-linguistic" and the first gesture-word combinations. They are part of an intersubjective multimodal communicative system in which it is more and more complex to tease apart gestures from speech. The performative, interactional and sociocultural nature of language involves the cooperation of both modalities, with one constantly supporting, extending or modifying the other.

We need to understand not only how the vocal modality or how the visual modality are used more and more skillfully by children, thanks to adults' scaffolding in everyday life interactions, but how the different channels and modalities work together. This perspective will give us better insights on how children become experts in face-to-face social interaction, which is necessarily multimodal in nature.

\section{References}

Arbib, Michael A. 2012 How the Brain Got Language, the Mirror System Hypothesis. Oxford/New York: Oxford University Press.

Blondel, Marion, Aliyah Morgenstern, Pauline Beaupoil, Sandra Benazzo, Dominique Boutet, Stéphanie Caët and Fanny Limousin 2011 The blossoming of negation in gesture, sign and vocal productions. Colloque international sur le langage de l'enfant. ADYLOC. Paris, Juin 2011.

Darwin, Charles 1877 A biographical sketch of an infant. Mind 2(7): 285-294.

Glenberg, Arthur M. and Michael P. Kaschak 2003 The body's contribution to language. In: Brian H. Ross (ed.), The Psychology of Learning and Motivation, Volume 43, 93-126. San Diego, CA: Academic Press.

Budwig, Nancy2003 Context and the dynamic construal of meaning in early childhood. In: Catherine Raeff and Janette B. Benson (eds.), Social and Cognitive Development in the Context of Individual, Social, and Cultural Processes, 103-130. London/New York: Routledge.

Butcher, Cynthia and Susan Goldin-Meadow 2000 Gesture and the transition from one- to two-word speech: When hand and mouth come together. In: David McNeill (ed.), Language and Gesture, 235-257. New York: Cambridge University Press.

Church, Ruth Breckinridge and Susan Goldin-Meadow 1986 The mismatch between gesture and speech as an index of transitional knowledge. Cognition 23(1): 43-71. 
Morgenstern, A. (2014). The blossoming of children's multimodal skills from 1 to 4 years old. In Cornelia Muller, Alan Cienki, Ellen Frickee, (Eds.). Body - Language - Communication. An international Handbook on Multimodality in Human Interaction. Berlin : De Gruyter Mouton. 1848-1857.

de Laguna, Grace Mead Andrus 1927 Speech: It's Function and Development. New Haven: Yale University Press

Duranti, Alessandro 1984 Intentions, self and local theories of meaning: Words and social action in a Samoan context. Center for Human Information Processing Report No. 122, La Jolla.

Estigarribia, Bruno and Clark Eve Vivien 2007 Getting and maintaining attention in talk to young children. Journal of Child Language 34(4): 799-814.

Goldin-Meadow, Susan 1999 The role of gesture in communication and thinking. Trends in Cognitive Science 3(11): 419-429.

Goldin-Meadow, Susan and Cynthia Butcher 2003 Pointing toward two-word speech in young children. In: Sotaro Kita (ed.), Pointing: Where Language, Culture, and Cognition Meet, 85-106. Mahwah, NJ: Lawrence Erlbaum.

Goldin-Meadow, Susan, Howard Nusbaum, Susan D. Kelly and Susan M. Wagner 2001 Explaining math: Gesturing lightens the load. Psychological Science 12(6): 516-522.

Levinson, Stephen C. 1983 Pragmatics. Cambridge: Cambridge University Press.

Mathiot Emmanuelle, Marie Leroy, Fanny Limousin and Aliyah Morgenstern 2009 Premiers pointages chez l'enfant sourd-signeur et l'enfant entendant: deux suivis longitudinaux entre 7 mois et 1 an 7 mois. Aile-Lia 1: 141-168.

McNeill, David1992 Hand and Mind: What Gestures Reveal About Thought. Chicago: University of Chicago Press.

McNeill, David2005 Gesture and Thought. Chicago: University of Chicago Press.

Morford, Marolyn and Susan Goldin-Meadow 1992 Comprehension and production of gesture in combination with speech in one-word speakers. Journal of Child Language 19(3): 559-580.

Morgenstern, Aliyah 2009 L'Enfant Dans La Langue. In collaboration with Sandra Benazzo, Marie Leroy, Emmanuelle Mathiot, Christophe Parisse, Anne Salazar Orvig and Martine Sekali. Paris: Presses de la Sorbonne Nouvelle.

Morgenstern, Aliyah and Christophe Parisse 2007 Codage et interprétation du langage spontané d'enfants de 1 à 3 ans. Corpus 6, Interprétation, contextes, codage: 55-78.

Morgenstern, Aliyah and Christophe Parisse 2012a The Paris corpus. French Language Studies 22(1): 7-12.

Morgenstern, Aliyah and Christophe Parisse 2012b Constructing "basic" verbal constructions: a longitudinal study of the blossoming of constructions with six frequent verbs. In: M. Bouveret and D. Legallois (eds.), Constructions in French, 127-154. Amsterdam: Benjamins. 
Morgenstern, A. (2014). The blossoming of children's multimodal skills from 1 to 4 years old. In Cornelia Muller, Alan Cienki, Ellen Frickee, (Eds.). Body - Language - Communication. An international Handbook on Multimodality in Human Interaction. Berlin : De Gruyter Mouton. 1848-1857.

Morgenstern, Aliyah, Stéphanie Caët, Marion Blondel, Fanny Limousin and Marie LeroyCollombel 2010 From gesture to sign and from gesture to word: pointing in deaf and hearing children. Gesture 10(2/3): 172-202.

Müller, Cornelia 2009 Gesture and language. In: Kirsten Malmkjaer (ed.), Routledge's Linguistics Encyclopedia, 214-217. London: Routledge.

Ochs, Elinor 2012 Experiencing language. Anthropological Theory 12(2): 142-160.

Özçalı kan, eyda and Susan Goldin-Meadow 2005 Gesture is at the cutting edge of early language development. Cognition 96(3): B101-B113.

Parisse, Christophe and Aliyah Morgenstern 2010 A multi-software integration platform and support for multimedia transcripts of language. LREC 2010, Proceedings of the Workshop on Multimodal Corpora: Advances in Capturing, Coding and Analyzing Multimodality, 106-110.

Romanes, Georges 1889 L'Évolution Mentale chez l'Homme. Origine des Facultés Humaines. Paris: Alcan. French translation [1891].

Scollon, Ron 1976 Conversations with a One-Year Old: A Case Study of the Developmental Foundations of Syntax. Honolulu: University Press of Hawaii.

Tomasello, Michael, Malinda Carpenter and Ulf Liszkowski 2007 A new look at infant pointing. Child Development 78(3): 705-722.

Zlatev, Jordan 1997 Situated Embodiment. Studies in the Emergence of Spatial Meaning. Stockholm: Gotab Press.

Zlatev, Jordan, Tomas Persson and Peter Gärdenfors 2005 Bodily Mimesis as "the Missing Link" in Human Cognitive Evolution. (LUCS 121.) Lund: Lund University Cognitive Studies.

Zlatev, Jordan and Mats Andrén 2009 Stages and transitions in children's semiotic development. In: Jordan Zlatev, Mats Andrén, Marlene Johansson-Falck and Carita Lundmark (eds.), Studies in Language and Cognition, 380-401. Newcastle: Cambridge Scholars.

Vygotsky, Lev S. 1978 Mind in Society. Cambridge, MA: Harvard University Press.

Werner, Heinz and Bernard Kaplan 1963 Symbol Formation: An Organismic Developmental Approach to Language and the Expression of Thought. New York: John Wiley. 